\title{
Ecology and decay pattern of Phellinus robustus in old-growth Quercus robur
}

\author{
STELLAN SUNHEDE and RIMVYDAS VASILIAUSKAS
}

\begin{abstract}
SUNHEDE, S. and VASILIAUSKAS, R. 2002: Ecology and decay pattern of Phellinus robustus in old-growth Quercus robur. - Karstenia 42: 1-11. Helsinki. ISSN 04533402 .

The biology of Phellinus robustus (P. Karst.) Bourdot \& Galzin (Hymenochaetales) was studied on Quercus robur L. in Lithuania, based on 677 host trees. Basidiocarp occurrence related to the diameter of the oaks and spatial distribution of basidiocarps on the trees are presented. Distribution of decay in eight sectioned, 110-175 year-old oaks showed one to three $0.1-5.8 \mathrm{~m}$ long, vertically separated rot columns. Vegetative compatibility tests indicated that each rot column was made up of a single genet of $P$. robustus and that the rot columns in the eight studied trees represented different genets. Infection routes, parasitic and saprotrophic behaviour, age of basidiocarps, forestry and biodiversity aspects are discussed. Illustrations show geographical distribution of the species in Lithuania, distribution of infected oaks in an old oak stand, frequency of infected trees related to diameter of the trunks, and distribution of decay in longitudinal and cross sections of trunks. Colour photos show distribution of white rot in the substrate, aerial mycelium on sectioned wood, and confrontation tests between cultivated mycelia of the same and different genets.
\end{abstract}

Key words: Biodiversity, decay pattern, ecology, forestry, Lithuania, Phellinus robustus, Quercus robur, vegetative incompatibility.

S. Sunhede, Department of Natural Sciences, University of Skövde, Box 408, SE54128 Skövde, Sweden

R. Vasiliauskas, Department of Forest Mycology and Pathology, Swedish University of Agricultural Sciences, Box 7026, SE-750 07 Uppsala, Sweden

\section{Introduction}

Phellinus robustus (P. Karst.) Bourdot \& Galzin is a cosmopolitan polypore (Larsen \& CobbPoulle 1990), which in Europe mainly occurs on Quercus spp. It is also known from many other deciduous trees (Kotlaba 1984, Ryvarden \& Gilbertson 1994). The species belongs to the $P$. robustus complex of the family Phellinaceae in Hymenochaetales (Obervinkler 1977, Jülich 1981, Fiasson \& Niemelä 1984). According to Ryvarden and Gilbertson (1994), P. robustus in Europe follows Quercus to southern Fennoscandia, although being mostly rare in that area. Phellinus robustus is classified as "vulnerable" in Denmark (Vesterholt \& Knudsen 1990), "rare" in Finland (Niemelä \& Kotiranta 1982, Kotiranta \& Niemelä
1996), and "conservation demanding" in Norway (Bendiksen et al. 1997). Until 1989, only one locality was known in Britain (Reid \& Dickson 1989).

However, in Sweden P. robustus is not a redlisted species and it is rather common in certain areas. In the Baltic states it was reported from Estonia (Parmasto 1993), Latvia (Smarods 1953, Rafalovich 1967), and Lithuania (Gricius \& Matelis 1996, Sunhede \& Vasiliauskas 1996). The species is found in major parts of Belarus (Komarova 1964) and is moderately common in Poland (Domański et al. 1973). Bondartsev (1971) noted that the species is common in the European USSR and in the Caucasus, wherever oaks and chestnut trees grow. 
In certain oak growing areas $P$. robustus is common to such an extent that it may constitute a major problem to forestry. In the Czech Republic and Slovakia $2.8 \%$ of the oaks were infected (Čerńy 1989), in Ukraine 1-13.7 \% (Taranenko 1973), and in Belarus 3.6\% (Novkau \& Galauko 1979). In the Kaliningrad region of Russia, $1.3-$ $37 \%$ of Quercus robur L. trees have stem and butt rots, one of the main causes of which is P. robustus (Maslov et al. 2000). In oak forests in the middle Volga region of Russia, the incidence of the fungus is also high, and the frequency of its infections increases with increasing severity of anthropogenic impact (Churakov 1992). In Minnesota (USA), about $4.3 \%$ of red oaks (Quercus rubra L.) were infected by $P$. robustus (French \& Perpich 1974).

In living $Q$. rubra, $P$. robustus causes cankers and decay that is essentially limited to the sapwood and heartwood behind the canker. The average length of the cankers was $37.2 \mathrm{~cm}$ and the average length of decay columns $92.7 \mathrm{~cm}$; they were situated 0.3-5.2 $\mathrm{m}$ aboveground (French \& Perpich 1974). However, much less is known about ecology, biology and silvicultural significance of $P$. robustus on pedunculate oak $(Q$. robur). Taranenko (1976) reported that, under laboratory conditions, wood of $Q$. robur was more resistant to $P$. robustus decay than was wood of $Q$. rubra. According to Hatsch et al. (1999), $P$. robustus in $Q$. robur causes minimal decrease in radial growth of the tree. The aim of our study is to provide more data on ecology, decay patterns, population structure and silvicultural significance of $P$. robustus on $Q$. robur.

\section{Materials and methods}

During the field work in Lithuania, 5455 trees and 742 cut stumps of Quercus robur were investigated with special emphasis on P. robustus. Position and number of basidiocarps of $P$. robustus on the oaks, outer damages on the trees, and diameter of the trunks (at $1.3 \mathrm{~m}$ above the ground) were registered on sites spread all over Lithuania (Fig. 1). The collections of P. robustus in the herbarium BILAS at the Botanical Institute in Vilnius were also examined. In Kauno Azuolynas Park (Kaunas) a map was constructed (based on Karazija 1990) in which the exact distribution of over 800 oaks with and without $P$. robustus is shown.

Eight living trees of Quercus robur attacked by Phellinus robustus were selected in Panevezys region of central Lithuania. The trees were measured and then felled with a chainsaw. A longitudinal scar was made in the bark along the trunk before the trunk was cross-sectioned into discs in order to orient the sections horizontally.
Sectioning started at the basidiocarps, continuing up and down along the trunk. Sections were made not only from the whole distinctly visible rot column, but also from fresh stem parts without visible decay. When the decay continued into branches, these were also sliced. In total, 177 stem discs were sawn from 8 trees (9-35 per tree). They were numbered, their thickness and position registered. The sections were transported to a field station for further studies. The horizontal distribution of the visible rot was registered with photographs, and for some trees also with drawings on transparent plastic sheet laid on each section. The age of the basidiocarps on the trees was estimated by counting the tube layers.

Probes for cultivation of vegetative mycelia of $P$ robustus were taken from each wood section (both inside and outside of the rot column) and from the basidiocarps. In the laboratory small wood pieces were cut out from the probes, their surfaces sterilised by flame, and then transferred into Petri dishes for growth on Hagem agar medium (Stenlid 1985). Outgrown mycelia were subcultured, transferred into test tubes for growth at $20^{\circ} \mathrm{C}$ in darkness, and then stored in a refrigerator at about $8{ }^{\circ} \mathrm{C}$. In total, 62 pure cultures (mycelial isolates) of $P$. robustus were obtained (3-19 per decay column). The isolates were used for vegetative incompatibility tests to see if one or several individual mycelia (genets) of $P$. robustus were present within a rot column and within a trunk. Self-compatibility tests and tests with mycelia from different sections and trees (from the same or distant localities) were made to check for mycelial interactions. The results of the compatibility tests were compared with field observations of the mycelia in the sectioned trunks.

\section{Results}

\section{Distribution}

We found $P$. robustus from the western to the eastern border of Lithuania and also collected it in the northern and southern parts of the country (Fig. 1). Basidiocarps were found on $Q$. robur in

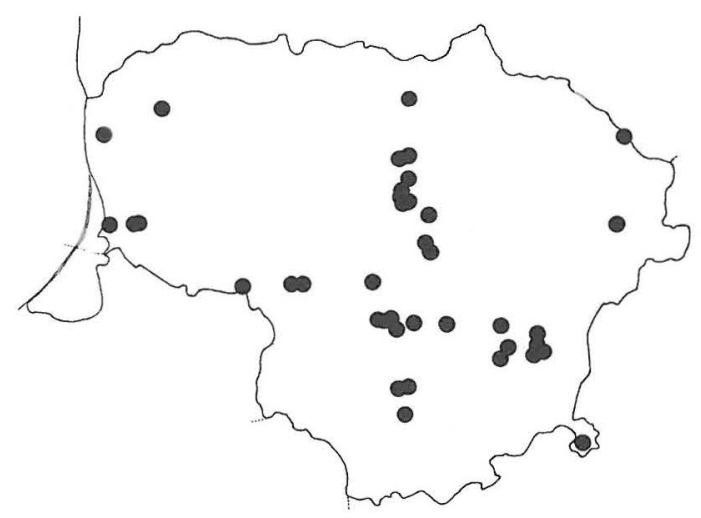

Fig. 1. Distribution of Phellinus robustus in Lithuania. 


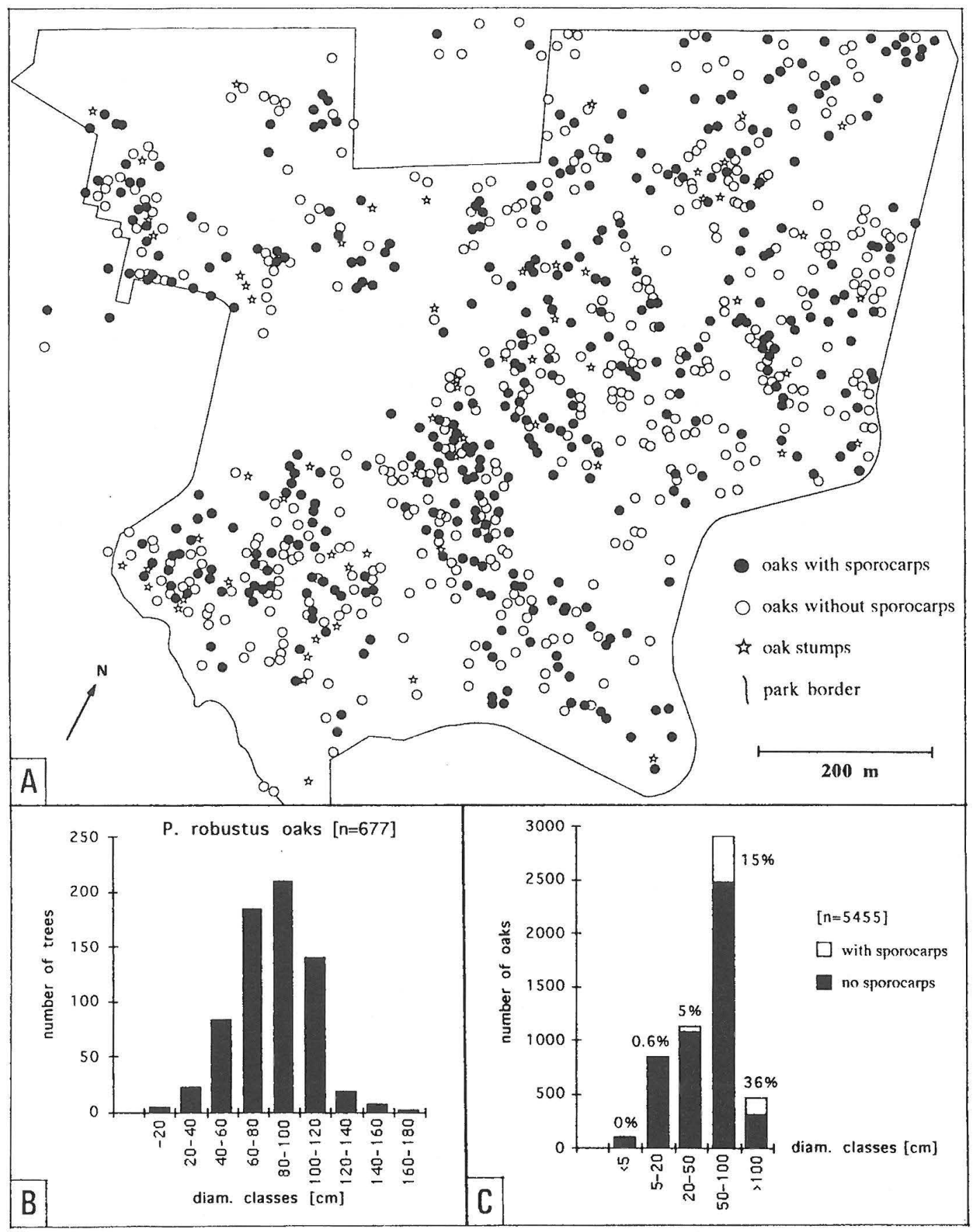

Fig. 2. Phellinus robustus on Quercus robur in Lithuania. - A: Spatial distribution of oaks in Kauno Azuolynas Park in Kaunas in 1996. - B: Distribution of $P$. robustus related to nine arbitrarily selected diameter classes of oak trees. - C: Number of investigated oaks during 1993 to 1996 grouped in five arbitrarily selected diameter classes. Percentage of oaks with basidiocarps of $P$. robustus also marked. - Drawings: Stellan Sunhede. 
pure oak stands, in mixed deciduous woods, mixed coniferous-deciduous woods, in parks, and on solitary trees.

\section{Basidiocarps}

In total, 677 (12.4\%) out of 5455 oaks investigated did bear basidiocarps of $P$. robustus. The distribution of $P$. robustus related to the diameter of the oaks is shown in Fig. 2 B. Only $0.6 \%$ of all trees with a diameter less than $20 \mathrm{~cm}$ had basidiocarps but the number of infected trees gradually increased with the diameter (or the age of the tree) and among 50-100 cm thick oaks 15\% had basidiocarps (Fig. 2 C). In one stand with old oaks (Kauno Azuolynas Park) 395 (48.6\%) out of 813 oaks were observed with basidiocarps (Fig. 2 A). No basidiocarps were found on the 742 investigated stumps of oaks. Basidiocarps were observed from one to several distinct locations on a tree. They appeared as single, a few, or many together on the same trunk. In one extreme case more than 60 basidiocarps (most of them inactive or dead) emerged in one area on the lower third of an old, half dead oak trunk.

Fresh basidiocarps were mostly found on living trunks or on living, 5-30 $\mathrm{cm}$ thick branches from the ground level up to the crown of the tree. However, oaks with basidiocarps near the base were rarely seen. Wide-crowned oaks more frequently had basidiocarps on their branches than had oaks in closed forests. Fresh basidiocarps were also found on half-dead or dead branches, on dead standing trunks, and sometimes also on fallen trees or fallen thick branches. On branches, they were distributed from the basal part to more than $5 \mathrm{~m}$ out from the trunk either on the main branch or on sub-branches. In many cases basidiocarps were located on or close to healing wounds after branches, on the remaining parts of broken branches (Fig. 4 A:b), and near broken tops of trunks. They often were observed in or close to distinct, bark-clad depressed areas. When associated with a depression they mostly occurred on its widest part (on or within its margins). Basidiocarps were rarely found on decorticated branches or on wood in shallow cavities made by woodpeckers.

Sectioned. basidiocarps showed annual growth layers varying from less than $1 \mathrm{~mm}$ up to $5 \mathrm{~mm}$ in thickness per year. Judging from the layers, some of them still actively growing appeared to be more than 35 years old. Field observations showed that basidiocarps were able to develop or to continue to grow on cut trunks or fallen thick branches. In one case a basidiocarp on a fallen trunk developed a new pileus on the old basidiocarp and perpendicular to it. The annual layers showed the old pileus to have grown for about 25 years on the living tree and new pileus (still living when collected) 12 years on the fallen substrate.

\section{Stem depressions (cankers)}

Many trees infected with $P$. robustus showed distinct "stem depressions" (cankers) associated with basidiocarps (Figs. 3 B; 4 J:arrows). The shape of well developed depressions were often fusiform, vertically oriented along the stems, and varying from quite small to up to $4.5 \mathrm{~m}$ long and $0.4 \mathrm{~m}$ wide. Similar but smaller depressions were also observed together with basidiocarps on branches. However, when basidiocarps occurred near the base of the trunks an acute triangular depression (with the base at the ground) developed. Distinct depressions of this type were 1.2$4.5 \mathrm{~m}$ high and $0.4-0.6 \mathrm{~m}$ wide at the base. Depressions were almost always bark clad and often surrounded by a distinct healing front (Figs. 3B:h; 4B-F, H). Cross sections through the stem showed the cambium to be dead in the depression zones and sometimes also revealed the presence of old healing fronts (Fig. 3 B, D). In many cases no or only a faint depression was observed around the basidiocarp.

\section{Decay in sectioned trees}

The following description is based on observations on horizontal sections of trunks. The first indication of the presence of $P$. robustus in the wood was rounded to elongated spots, darker than, but as hard as, the surrounding wood (Fig. $4 \mathrm{I}: \mathrm{dw})$. In time, these spots increased in size, fastest so in the direction of the annual rings, and melting together into larger units of variable pattern (Fig. 4 I, G, E). Within the dark areas the wood gradually became whitish and soft in spots or strands following the annual rings. In time the whitish spots and strands increased and fused, eventually forming an area of uniform white rotted wood (Fig. 4 B:ww). This area was surrounded by a darker, narrow to broad zone of hard 

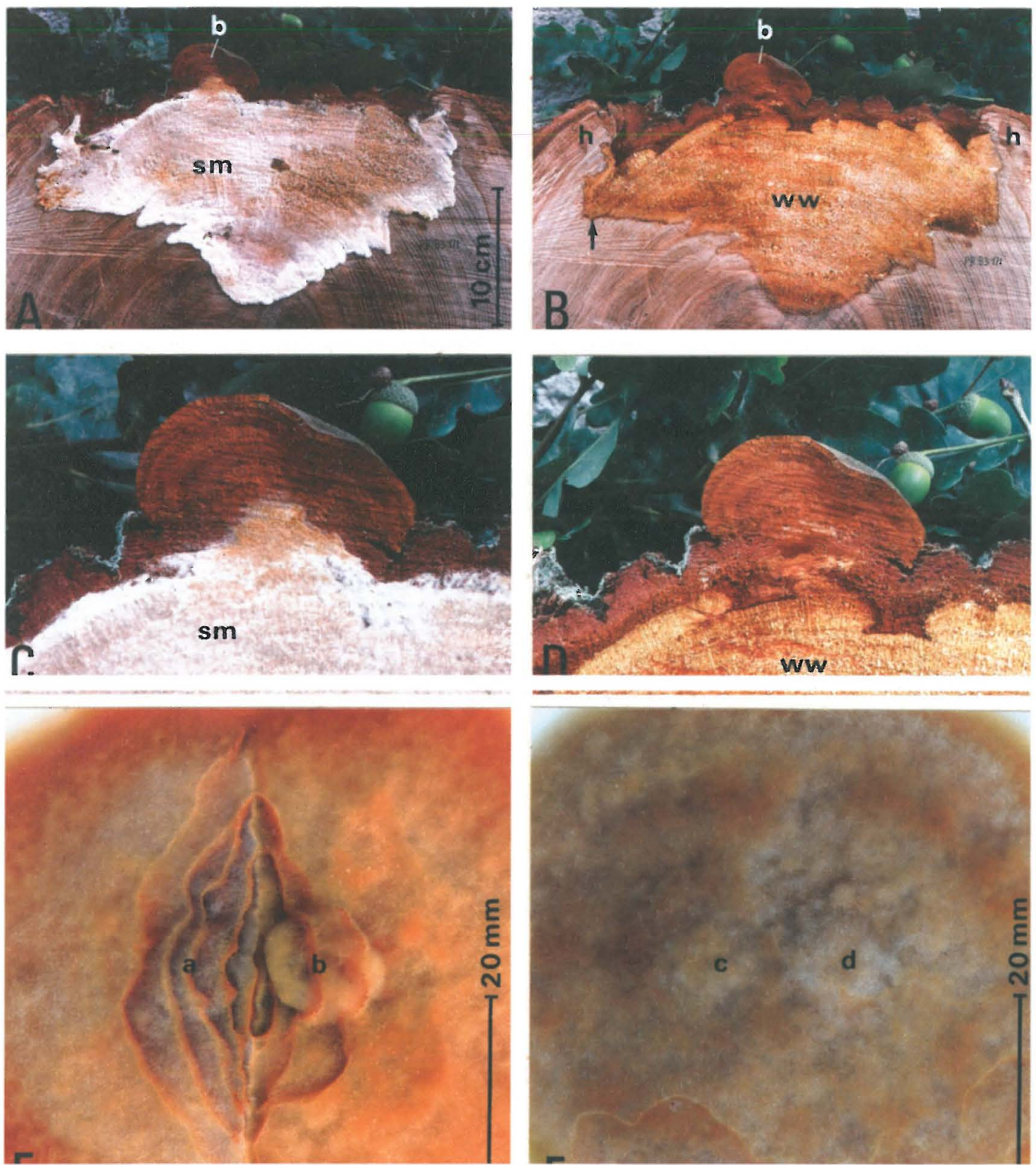

Fig. 3. Mycelial activities of Phellinus robustus. - A-D: Part of the same slice of a horizontally sectioned trunk of Quercus robur with attached basidiocarp $(=\mathrm{b})$. $-\mathrm{A}$ : With outgrown, somatic surface mycelium $(=\mathrm{sm})$. - B: Same view as (A) but surface mycelium scraped off. Demonstrated are the extension of a white rot column $(=$ ww) in the wood, a brown borderline (arrow), two active healing zones $(=h)$ at each side of a depression and several former healing zones, dead cambium, and still attached bark. - C, D: Details of (A) and (B), respectively. - E: Confrontation zone between two genetically different mycelia, grown on Hagem agar, inoculated at (a) and (b), respectively. - F: Absence of confrontation zone between isolations from a single genet, (c) and (d), respectively. - Photos: Stellan Sunhede. 

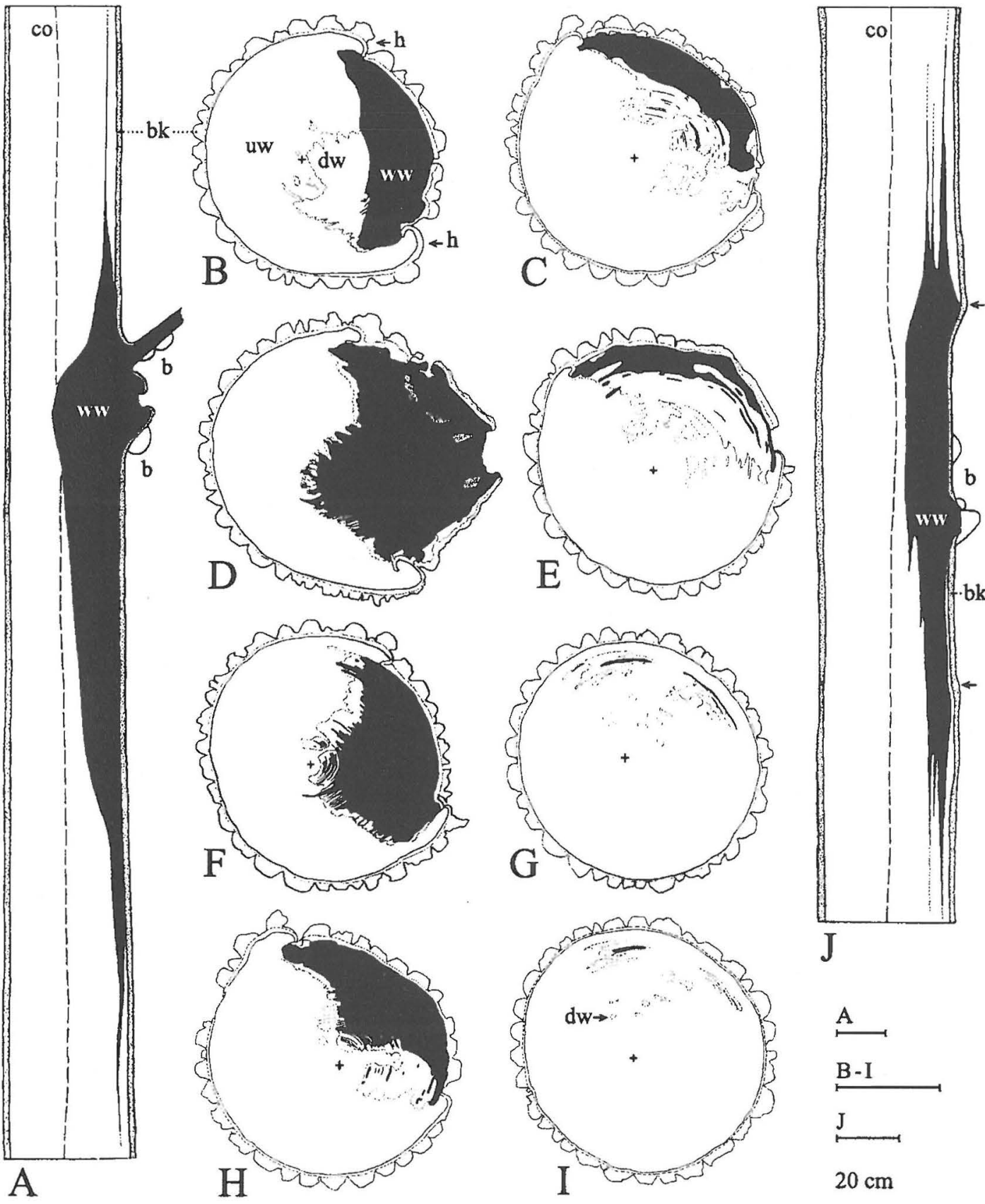

Fig. 4. Decay of Phellinus robustus in sectioned stems of Quercus robur. - A, J: Longitudinal, central sections showing decay columns (black, basidiocarps (b), and stem depression between arrows). - B-I: Cross sections through (A) at different levels of the trunk; (B) above, (D) at, and (C, E-I) below the widest part of the rot column. - bk= bark, co and $+=$ pith of the wood, $\mathrm{dw}=$ discoloured hard wood (delimited by faint lines), $\mathrm{h}=$ healing front, $\mathrm{uw}=$ unaffected wood, ww $=$ white rotted wood. - Drawings: Stellan Sunhede. 
Table 1. Main parameters of analysed Quercus robur trees and Phellinus robustus decay columns.

\begin{tabular}{|c|c|c|c|c|c|c|c|}
\hline \multicolumn{4}{|c|}{ Tree parameters } & \multicolumn{4}{|c|}{ Decay column parameters } \\
\hline \multirow[t]{2}{*}{ no. } & \multirow{2}{*}{$\begin{array}{c}\text { age } \\
\text { (years) }\end{array}$} & \multirow{2}{*}{$\begin{array}{l}\text { diameter at } \\
\text { breast height } \\
(\mathrm{cm})\end{array}$} & \multirow{2}{*}{$\begin{array}{l}\text { height } \\
\text { (m) }\end{array}$} & \multirow{2}{*}{$\begin{array}{l}\text { columns } \\
\text { per tree }\end{array}$} & \multicolumn{2}{|c|}{ limits in stem (m) } & \multirow{2}{*}{$\begin{array}{l}\text { total length } \\
\text { (m) }\end{array}$} \\
\hline & & & & & lower & upper & \\
\hline 1. & 110 & 45 & 21.4 & 1 & 3.5 & 7.2 & 3.7 \\
\hline \multirow[t]{2}{*}{2.} & 170 & 58 & 27.6 & 2 & 6.1 & 9.2 & 3.1 \\
\hline & & & & & 11.3 & 11.4 & 0.1 \\
\hline 3. & 160 & 59 & 29.9 & $3^{A}$ & 3.4 & 8.3 & 4.9 \\
\hline 4. & 170 & 48 & 26.0 & 1 & 1.4 & 7.2 & 5.8 \\
\hline \multirow[t]{2}{*}{5.} & 175 & 43 & 22.6 & 2 & 2.8 & 6.0 & 3.2 \\
\hline & & & & & 6.3 & 10.0 & 3.7 \\
\hline 6. & 175 & 59 & 23.4 & 1 & 5.1 & 10.5 & 5.4 \\
\hline 7. & 152 & 44 & 26.2 & 1 & 5.4 & 6.7 & 1.3 \\
\hline 8. & 150 & 45 & 20.2 & 1 & 2.7 & 4.7 & 2.0 \\
\hline Mean & 158 & 50 & 24.7 & 1.4 & 4.8 & 8.1 & 3.3 \\
\hline $\mathrm{SD}$ & 22 & 7 & 3.3 & & 2.8 & 2.1 & 1.8 \\
\hline
\end{tabular}

A The parameters of only one decay column were estimated in this stem; second unmeasured column was situated about $1.5 \mathrm{~m}$ higher up on the stem and was caused by another genotype of the fungus; third column was mainly restricted to an $8-9 \mathrm{~cm}$ thick broken branch about $15 \mathrm{~m}$ above the ground.

wood, which sometimes split into separate spots at its outer border (Fig. 4 B:dw, C-F). In the trunks the decay process started peripherally. Part of the decay reached the periphery of the wood rather soon but as the mycelium also grew inwards and side-wards, the rot in due course reached and exceeded the centre of the trunk (Figs. 3 B; 4 B-I). At its widest part the decay column occupied up to $45 \%$ of the sectioned stem discs.

In vertical sections of the trunks, $P$. robustus formed a fusiform decay column, sometimes split at its ends (based on 12 rot columns; cf. Fig. 4 A, J). The vertical extension of the decay columns varied depending on age of the infection from 0.1 to $5.8 \mathrm{~m}$ (Table 1). In cases where two or three columns were present within a single trunk (trees no 2, 3, and 5), a total length of 3.2-6.9 $\mathrm{m}$ was degraded by $P$. robustus (Table 1 ). In one oak (with three decay columns of $P$. robustus) one decay column was mainly restricted to an $8-9 \mathrm{~cm}$ thick broken branch about $15 \mathrm{~m}$ above the ground. A small basidiocarp was attached at the side of the branch $0.4 \mathrm{~m}$ from the trunk. The rot continued into the $0.4 \mathrm{~m}$ thick stem where it occupied just a shallow rot pocket not exceeding 0.5 $\mathrm{dm}^{3}$. Full characteristics of examined trees and rot columns are presented in Table 1.

\section{Mycelia and genets}

The somatic mycelium of $P$. robustus was not visible to the naked eye on the surface of newly sectioned stem discs. However, on wood sections stored under insufficient drying conditions the mycelium grew out from the wood and appeared on its surface (Fig. 3 A, C). The 1-2 week old mycelial layer was up to $2 \mathrm{~mm}$ thick. It was whitish as young, later becoming light greyish beige to brown. When bruised it turned dark brown and when scraped off the surface the white rotted wood showed a yellowish to ochraceous colour (Fig. 3 B, D). The mycelium grew from the hard, brownish stained wood, the white rotted wood, the killed cambium, parts of the bark, and from the base of the basidiocarp but no mycelial growth occurred from the visibly unchanged wood (Fig. 3 A-D). In well decayed and easily bro- 
ken wood (with whitish irregular patterns of cellulose) a cottony, whitish to brownish ochraceous, somatic mycelium of $P$. robustus was observed under lens in small cracks and cavities.

The somatic mycelium grew both aerial and submerged on Hagem agar. The aerial mycelium was ochraceous to yellowish brown, had a cottony surface (Fig. 3 E, F), and a \pm well delimited, uneven margin. The submerged mycelium advanced faster than the aerial mycelium. In selfcompatibility tests the compatible mycelia merged nicely together as one entity and no borderline occurred between the two isolates (based on 336 pairings; Fig. 3 F). There was no change of colour of the agar. Confronted incompatible mycelia showed a distinct superficial confrontation zone of varying appearance (based on 64 pairings). In its simplest appearance the zone was a narrow ditch or a fold-like front between the two isolates. However, often there were $1-4$ additional folds (parallel or as bulges) on each side of the central zone (Fig. 3 E). The agar under the confrontation zone (seen from the bottom of the Petri dish) was stained dark brown. Confrontation tests between mycelial isolates from a single rot column showed no confrontation zone. Tests between mycelial isolates from different rot columns (from a single or from different trees) showed distinct confrontation zone. These results indicate that the eight sectioned oaks were attacked by $1,1,1,1,1,2,2$, and 3 mycelia of $P$. robustus, respectively. All mycelia were confronted with one another. All showed a distinct confrontation zone, indicating that they represented different genets. When two or three mycelia occurred in a single tree they were well separated and found at different levels in the trunk. Field observations on old, wide-crowned oaks in Kaunas indicate that up to 6 individual mycelia may be present in the same tree. In these trees basidiocarps grow so far away from each other (on trunks or on different branches) that they most probably belong to different mycelia.

\section{Borderlines}

The white rotted wood, as seen in sectioned stem discs, was delimited by a darker zone towards the visibly unaffected wood (Fig. 3 B: arrow). A distinct dark brown borderline was also observed at the border zone towards an adjacent decay of Inocutis dryophila (Berk.) Fiasson \& Niemelä.
No borderline zones were observed within the white rot column itself. However, if the stem discs were stored for 1-2 weeks under dark and slowly drying conditions, very distinct, dark brown borderlines, thin as a thread, developed within the white rotted wood (seen as an irregularly undulating line, 2-6 mm under each of the two opposite surfaces, in vertically sectioned discs).

\section{Discussion}

The distribution map of $P$. robustus in Lithuania (Fig. 1) was based on specimens seen by us in the field or in the herbarium BILAS. It shows the fungus to be spread all over the country even if there are large areas that have not yet been investigated. As we have seen $P$. robustus also in geographically isolated oak stands and on isolated single oaks we believe that careful investigations in the less oak-rich areas will reveal many new finds in presence of suitable substrate. The species was most frequently found in the oakrich districts of Kaunas, Panevežys and Vilnius.

In Lithuania $P$. robustus (judging from presence of basidiocarps) seems not to thrive in young oaks (Fig. 2 B, C) even if infection potential is high. For example, in Gustonys (Panevezys distr.) 377 planted oaks about 30 year old, 5-22 cm thick, had no basidiocarps, in spite of the occurrence of $P$. robustus on older oaks in adjacent stands and in spite of the many damages (ca. $69 \%$ of the oaks had wounds after bark stripping by red deer, Cervus elaphus L.) which might serve as possible infection sites. During previous study, $P$. robustus fruitbodies were also absent on $30-50$ year-old oaks with bark stripping damage, despite the fruitbodies of other wood decay basidiomycetes were found on $6 \%$ of damaged trees (Vasiliauskas 1998). Investigations in Sweden on numerous oaks (Sunhede unpublished) also show that trees less than $20 \mathrm{~cm}$ in thickness very rarely have mycelia that produce basidiocarps.

The very high incidence of $P$. robustus (48\% infected oaks; Fig. 2 A) observed in Kauno Azuolynas Park was in fact probably still higher as: (1) several oaks without basidiocarps showed cankers characteristic of $P$. robustus, (2) basidiocarps situated high up in some of the oaks may have been overlooked, and (3) probably even some still healthy looking trees were also attacked even if no visible sign of infection had yet 
occurred. There are some probable reasons, explaining the high infection incidence in this park: (1) the old age of the oaks have given the fungus a long time for colonisation, (2) the frequent cutting of branches during long periods of time (for public safety and other reasons) caused additional wounds where infection of the fungus could start, and (3) wind exposition caused more branch breaks in the wide-crowned oaks of the rather open park than on oaks with smaller canopies growing sheltered in the closed forests. The high infection percentage of the old oaks in the park strongly affects the result in Fig. $2 \mathrm{C}$ where the percentage for the five diameter classes were $0,0.6,5,15$, and $36 \%$. If the oaks of the park were excluded the more moderate corresponding values would be: $0,0.6,1.7,3$, and $5 \%$, respectively.

In literature, decay caused by $P$. robustus was previously referred to as white rot of heartwood of living Quercus trees (Davidson et al. 1942, Ryvarden \& Gilbertson 1994). Rypáèek (1966) noted that the species caused white rot and stated that the rot started in the core of the tree and spread out to the splint wood. According to our observations, the species causes white rot but is no heart-rotter. On the contrary, decay spreads in the opposite direction from the periphery towards the core and is able to decompose the sapwood even attacking the cambium (Figs. 3 B; 4).

According to Čerńy (1989), living stems were infected by P. robustus through the bases of broken branches. This agrees very well with our data. In Lithuania, we observed basidiocarps of $P$. robustus associated with branches in more than $85 \%$ of the cases, occurring at the base of or on living branches, on dead branches or remains of branches, and on healing wounds after branches. Holmer et al. (1994) found Phellinus tremulae (Bond.) Bond. \& Borisov in small twigs of Populus tremula $\mathrm{L}$. and commonly detected as many as four genotypes of the fungus within a single stem. Whether small oak twigs could serve as an infection site for $P$. robustus is not known, but it seems unlikely for several reasons. First, in most cases only one $P$. robustus genotype per tree was found during the present work, indicating that the access for the fungus into the stem is rather restricted. Second, the basidiocarps were recorded only at the bases of much thicker, up to 5-6 cm thick branches attached to the stem or far out on thicker branches. No infection by grafting of fallen branches as seen in Phellinus ferreus
(Pers.) Bourdot \& Galzin (Sunhede 1998) was observed. Gilbertson and Ryvarden (1987) indicate that the basidiocarps of $P$. robustus in North America commonly develop near the base of living oaks. By contrast, only few finds of basidiocarps were made on the base near the ground on oaks in Lithuania during the present work. The same is valid for Sweden (Sunhede unpublished). In this case infection sites might be through mechanical damages on root collars or on lower parts on the trunk caused by, for example, trampling and gnawing by animals, or caused by forest vehicles and frost.

Many authors note $P$. robustus to be parasitic (Domański et al. 1973, Cheremisinov 1976, Jahn 1979, Rypáček 1966, Ryvarden \& Gilbertson 1994, Hatsch et al. 1999). Our study supports this and clearly indicates that $P$. robustus shows necrotrophic behaviour while killing the cambium. Its activity may result in rather large stem depressions or cankers, as noted also by French and Perpich (1974). On the other hand, growth losses in oaks due to $P$. robustus attack are minimal (Hatsch et al. 1999) and the fungus rapidly decomposes wood blocks under laboratory conditions (Aufsess 1973, Taranenko 1976), beeing able to thrive as a saprotroph. Moreover, the largest portion of a tree consists of dead wood, which also is readily decomposed by the fungus (Figs. $3 \mathrm{~B}$; 4), and in nature the presence of a living cambium is not necessary for the survival of $P$. robustus as it is able to continue as a true saprotroph in fallen trunks or thick branches for many years. Most of our field observations clearly indicate that $P$. robustus was already present in the substrate before it fell to the ground. Whether the fungus is able to establish itself on recently dead wood is not known, but most likely it would be outcompeted by a number of other organisms better adapted to colonize freshly exposed substrate.

In this study the genets were separated by incompatibility tests. All our incompatibility and self compatibility tests were distinct and uniform, thus making the results easy to interpret. Since $P$. robustus is a homothallic species (Fischer 1996), it makes possible for each decay column to be initiated by a single spore. Therefore, homothallism in P. robustus may be an advantage in the colonisation process, since there is no need to pair for different spores before or while entering the living tree. After infection and colonization, the fungus exhibits high persistence within the 
woody tissues of oak. By counting the number of tube layers in the basidiocarps of $P$. robustus we could estimate a minimum age of the mycelium and decay in the tree. In Lithuania we have observed 37 year old basidiocarps. From Sweden one basidiocarp showed more than 50 layers (Sunhede unpublished). However, we do not know the age of the mycelium before it produced the basidiocarps, nor to what extent it will grow after the basidiocarps are dead.

\section{Forestry aspects}

When destroying the wood in living trees, the decay of $P$. robustus may cause losses to forestry (Figs. $3 \mathrm{~B}$ : ww; 4). To the forester the presence of cankers and/or basidiocarps is the first sign of infection. Our data indicates, that at this stage the fungus very likely has already formed a well developed rot column within the trunk. Čerńy (1989) suggested to reduce the infection potential of $P$. robustus by continuous removal of trees with basidiocarps from forest stands, thus by cutting mostly old-growth oak trees. Here we would like to emphasize that there are several important reasons for not doing so: (1) the costs of cutting large-sized decayed trees will be high; (2) economic revenue will be low, since it is known that even minor injuries on old oaks reduce the price for wood drastically (Kehr \& Wulf 1991); (3) in reality it will be difficult to detect basidiocarps high up in the trees, to eliminate them from fallen branches and trunks, and to prevent dispersal from infected trees in environments outside the forest stands; (4) the aim of reducing infection potential thus will not be achieved since the basidiospores of wood decay fungi may travel over hundreds of kilometres and common species are effectively distributed over large areas (Stenlid \& Gustafsson 2001); (5) although P. robustus itself is not an endangered species and even is likely to occur more often in areas under increasing anthropogenic impact (Churakov 1992), oaks decayed by the fungus often provide nesting shelter for birds, thus beeing important for nature conservation (Hatsch et al. 1999; Ryman \& Holmåsen 1991 p. 186); (6) old-growth oaks are of great general importance to biodiversity, since they provide habitat for many species of endangered insects (Jonsell et al. 1998) and fungi (Sunhede \& Vasiliauskas 2003). However, in areas where oaks are industrial species and $P$. robustus is frequent, shortening of the rotation period in certain stands may be considered as one possibility to minimise damage caused by this fungus.

Acknowledgments: We are very grateful to Prof. Albertas Vasiliauskas for his help in carrying out the field work in Lithuania from 1993 to 1996 . We are also indebted to Drs Antanas Matelis, Jurga Motiejunaite and Vincentas Urbonas for excursions made during 1993 and for valuable help in the botanical herbarium (BILAS) in Vilnius. The support from local forest administrators and foresters highly facilitated the field work. Especially, we want to thank Algimantas Burda and Jonas Dumbra. Late Mr. Eugenius Juska kindly helped us with part of the field work in Kauno Azuolynas park. We also owe our gratitude to Professors Erast Parmasto and Jan Stenlid for valuable information and Uno Eliasson, Nils Hallenberg, Tuomo Niemelä, and Leif Ryvarden for critical reading of the manuscript. Jan Stenlid also generously put laboratory facilities at our disposal. Financial support was received from the Ministry of forestry of Lithuania, Kapten Carl Stenholms Fond, The Royal Society of Arts and Sciences in Göteborg, and The Swedish Institute. The support is gratefully acknowledged.

\section{References}

Aufsess, H.V. 1973: Fungus damage on old (veneer) oaks. - Forstwiss. Centralbl. 92: 153-169.

Bendiksen, E., Højland, C., Branderud, T.E., Jordal, J.B. 1997: Truede og sårbare sopparter i Norge - en kommentert rødliste. - Fungiflora, Oslo. 221 pp.

Bondartsev, A .S. 1971: The polyporaceae of the European USSR and Caucasia (Trutovye griby evropeyskoy chasti SSSR i Kavkaza. - Izdatel'stvo Akad. Nauk SSSR, Moskva \& Leningrad. 1106 pp.). - Jerusalem. 896 pp.

Čerńy, A. 1989: Parazitické drevokazné houby. - Statní zemědelski nakladatelstvo, Praha. 99 pp.

Cheremisinov, N.A. 1976: Trutovye griby - parazity derev'ev. - Zaschita Rasteniy 9: 34-36.

Churakov, B.P. 1992: Vlijanie rekreatsionnykh nagruzok na porazhaemost duba (Quercus robur) trutovymi gribami v lesakh srednei Volgi. - Lesn. Zhurn. 2: 116 118.

Davidson, R.W., Campbell, W.A. \& Blaisdell Vaughn, D. 1942: Fungi causing decay of living oaks in the Eastern United States and their cultural identification. U. S. Dept. Agr. Tech. Bull. 785: 1-75.

Domański, S., Orłoś, H. \& Skirgiełło, A. 1973: Polyporaceae 2. - Ganodermataceae, Bondarzewiaceae, Boletopsidaceae, Fistulinaceae. - Warsaw. 332 pp.

Fiasson, J.L. \& Niemelä, T. 1984: Hymenochaetales: a revision of the Europaean poroid taxa. - Karstenia 24: 14-28.

Fischer, M. 1996: On the species complexes within Phellinus: Fomitiporia revisited. - Mycol. Res. 100: 1459-1467.

French, D.W. \& Perpich, F.W. 1974: Cankers and decay in red oaks caused by Fomes robustus. - Phytopathology 64: 1148- 1149 . 
Gilbertson, R.L. \& Ryvarden, L. 1987: North American Polypores 2. Megasporoporia - Wrightoporia. - Fungiflora, Oslo. 434-885 pp.

Gricius, A. \& Matelis, A. 1996: Mycota Lithuaniae VI. Aphyllophorales 2. - Hymenochaetaceae, Fistulinaceae, Ganodermataceae, Polyporaceae. - Mokslo ir enciklopediju leidykla, Vilnius. $232 \mathrm{pp}$.

Hatsch, E., Dupouey, J.L., Dubreuil, B. \& Guillaud, J. 1999: Impact du champignon parasite Phellinus robustus et des cavites nidifiables sur la croissance des chenes sessile et pedoncule. - Rev. Forest. Franç. 51: $511-521$.

Holmer, L., Nitare, L. \& Stenlid, J. 1994: Population structures and decay pattern in Phellinus tremulae as determined by somatic inompatibility. - Canad. J. Bot. 72: 1391-1396.

Jahn, H. 1979: Pilze die an Holz wachsen. - Busse, Herford. $268 \mathrm{pp}$.

Jonsell, M., Weslien, J. \& Ehnström, B. 1998: Substrate requirements of red-listed saproxylic invertebrates in Sweden. - Biodiv. Conserv. 7: 749-764.

Jülich, W. 1981: Higher taxa of Basidiomycetes. - Bibl. Mycol. 85: 1- 485 .

Karazija, S. (ed.) 1990: Nustatyti priemones Kauno auzuolyno buklei pagerinti (On the possibilities to improve condition of Kauno azuolynas park). - Lietuvos Misku institutas. $120 \mathrm{pp}$.

Kehr, R. \& Wulf, A. 1991: Schwerwiegende Schäden an Alteichen durch Baumfrevel. - Nachrichtenbl. Deut. Pflanzenschutzd. 43: 133-134.

Kotiranta, H. \& Niemelä, T. 1996: Uhanalaiset käävät Suomessa. - Edita, Helsinki. 184 pp.

Komarova, E.P. 1964: Opredelitel' trytovykh gribov Belorusii. - Nauka i Tekhnika Minsk. 343 pp.

Kotlaba, F. 1984: Zemepisné rozsírení a ekologie chorosů /Polyporales s.1./ v Československu. - Academia, Praha. 194 pp.

Larsen, M.J. \& Cobb-Poulle, L.A. 1990: Phellinus (Hymenochaetaceae). A survey of the world taxa. - Synopsis Fungorum 3: 1-206.

Maslov, A.D., Komarova, I.A. \& Sergeeva, Y.A. 2000: Sostoyanye dubovykh lesov Kaliningradskoy oblasti. - Lesnoe Khozyaistvo 3: 48-50.

Niemelä, T. \& Kotiranta, H. 1982: Polypore survey in Finland 2. The genus Phellinus. - Karstenia 22: 27 42.

Novkau, M.A. \& Galauko, A.I. 1979: Derevorazrushayuschye griby dubovykh nasazhdeniy Zhornovskoy lesoopytnoy stantsii. - Vesti Akademii Navuk BSSR, Bialagichnykh Navuk 1: 60-64.
Oberwinkler, F. 1977: Das neue System der Basidiomyceten. - In: Frey, W., Hurka, H. \& Oberwinkler, F. (eds.). Beiträge zur Biologie der niederen Pflanzen: 59-105.

Parmasto, E. 1993: Distribution maps of Estonian Fungi. Eesti seente levikuatlas. 1 Hymenochaetaceae taelikulised. - Tartu 1993.

Rafalovich, L. 1967: On polypore fungi flora in Latvian SSR. - Latvijas PSR Zinatnu Academija Vestis 3 (236): 91-95.

Reid, D.A. \& Dickson, G. 1989: Occurrence of Phellinus robustus in Britain. - Mycol. Res. 92: 108-109.

Ryman, S. \& Holmåsen, I. 1991: Svampar. En fälthandbok. - Interpublishing, Stockholm. 718 pp.

Rypáček, V. 1966: Biologie Holzzerstörender Pilze. Jena. $211 \mathrm{pp}$

Ryvarden, L. \& Gilbertson R.L. 1994: European Polypores 2. Meripilus - Tyromyces. - Fungiflora, Oslo. 388-743 pp.

Smarods, J. 1953: Some new data about Hymenomycetes of the Latvijan SSR. - Latvijas PSR Zinatnu Academija Vestis 2 (67): 61-73.

Stenlid, J. 1985: Population structure of Heterobasidion annosum as determined by somatic incompatibiöity, sexual incompatibility and isoenzyma patterns. - Canad. J. Bot. 63: 2268-2273.

Stenlid, J. \& Gustafsson, M. 2001: Are rare wood decay fungi threatened by inability to spread? - Ecol. Bull. 49: $85-91$.

Sunhede, S. 1998: Vedsvampar på ek - 6. Västlig rostticka, Phellinus ferreus. - Ekbladet 13:14-18.

Sunhede, S. \& Vasiliauskas, R. 1996: Wood and bark inhabiting fungi on oak in Lithuania. - Baltic Forestry 2: $23-27$.

Sunhede, S. \& Vasiliauskas, R. 2003: Hotade tickor på ek i Litauen. - Svensk Bot. Tidskr.

Taranenko, P.K. 1973: Morfologichni ta kul'tural'ni osoblivosti griba Phellinus robustus (Karst.) Bourd. \& Galz. zalezhno vid urazhennya nim riznikh vidiv duba. - Ukrayins'k. Bot. Zhurn. 30: 64-72.

Taranenko, P.K. 1976: Testing the resistance of wood of different species of oak to Phellinus robustus in laboratory conditions. - Lesn. Zhurn. 3: 21-23.

Vasiliauskas, R. 1998: Patterns of wounding and decay in stems of Quercus robur due to bark peeling. - Scand. J. Forest Res. 13: 437-441.

Vesterholt, J. \& Knudsen, H. 1990: Truede storsvampe i Danmark - en rødliste. - Foreningen til Svampekundskapens Fremme, Søborg. 64 pp. 